Gelanggang Olahraga: Jurnal Pendidikan Jasmani dan Olahraga

Volume 2, Nomor 2, Januari-Juni 2019

e-ISSN : 2597-6567

p-ISSN : 2614-607X

DOI : https://doi.org/10.31539/jpjo.v2i2.482

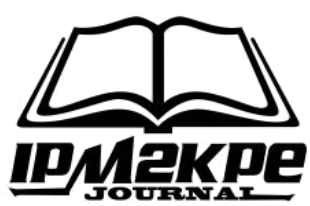

\title{
TINJAUAN KONDISI FISIK ATLET BOLABASKET
}

\author{
Hendri Mulyadi ${ }^{1}$, Badri Nikon ${ }^{2}$ \\ Pendidikan Jasmanis, Kesehatan dan Rekreasi STKIP Rokania ${ }^{1,2}$ \\ hendrimulyadi999@gmail.com ${ }^{1}$
}

\begin{abstract}
ABSTRAK
Penelitian ini bertujuan untuk mengetahui seberapa baik kondisi fisik yang dimiliki atlet bolabasket SMK Negeri 1 Pulau Punjung yang berkenaan dengan daya tahan, kekuatan, kecepatan, kelincahan dan daya ledak otot tungkai.Jenis penelitian ini merupakan penelitian deskriptif. Populasi pada penelitian ini adalah atlet bolabasket SMK Negeri 1 Pulau Punjung yang berjumlah 37 orang. Penarikan sampel dilakukan dengan Purposive Sampling, maka sampel berjumlah 25 orang. Setelah data didapat, maka teknik analisis data dalam penelitian ini menggunakan tabulasi frekwensi. Hasil penelitian ini menunjukkan : 1) tinjauan daya tahan yang dominan dimiliki atlet bolabasket SMK Negeri 1 Pulau Punjung adalah 10,59 - 13,25 tergolong kategori baik $(60 \%)$, 2) tinjauan kekuatan yang dominan dimiliki atlet bolabasket SMK Negeri 1 Pulau Punjung adalah 57,5078,00 tergolong kategori sedang (64\%), 3) tinjauan kecepatan yang dominan dimiliki atlet bolabasket SMK Negeri 1 Pulau Punjung adalah 4,97 - 5,40 tergolong kategori sedang $(32 \%)$, 4) tinjauan kelincahan yang dominan dimiliki atlet bolabasket SMK Negeri 1 Pulau Punjung adalah 14,10 - 15,74 tergolong kategori sedang $(14 \%), 5)$ tinjauan daya ledak otot tungkai yang dominan dimiliki atlet bolabasket SMK Negeri 1 Pulau Punjung adalah 31 - 38 tergolong kategori sedang $(72 \%)$.
\end{abstract}

Kata Kunci : Kondisi Fisik, Atlet Bolabasket.

\begin{abstract}
This study aims to find out how well the physical conditions possessed by basketball athletes at SMK Negeri 1 Pulau Punjung that are related to endurance, strength, speed, agility and explosive strength of limb muscles. This type of research is a descriptive study. The population in this study were 37 basketball athletes from SMK Negeri 1 Punjung Island. Sampling was done by Purposive Sampling, then the sample amounted to 25 people. After the data is obtained, the data analysis technique in this study uses frequency tabulation. The results of this study indicate: 1) a dominant review of durability possessed by basketball athletes at SMK Negeri 1 Punjung Island is 10.59 - 13.25 classified as good category (60\%), 2) review of the dominant strength possessed by basketball athletes at SMK Negeri 1 Punjung Island is 57.50 - 78.00 classified as medium category (64\%), 3) review of the dominant speed possessed by basketball athletes at SMK Negeri 1 Pulau Punjung is 4.97 - 5.40 classified as medium category (32\%), 4)
\end{abstract}


agility review the dominant possession of basketball athletes at Pulau Punjung State Vocational High School 1 was 14.10-15.74 classified as medium category (14\%), 5) review of leg muscles explosive power dominantly owned by basketball athletes in Pulau Punjung State Vocational High School was 31-38 classified as medium $(72 \%)$.

Keywords: Physical Condition, Basketball Athletes.

\section{PENDAHULUAN}

Olahraga merupakan aktifitas fisik yang dilakukan seseorang dengan cara sadar. Aktivitas manusia dalam kehidupan sehari - hari berguna untuk membentuk jasmani dan rohani yang sehat. Sampai saat ini olahraga telah memberikan kontribusi yang positif, dalam meningkatkan kesehatan. Olahraga diindonesia tidak hanya untuk kepentingan Pendidikan, Rekreasi, dan Kesegaran Jasmani, tetapi juga sebagai ajang prestasi. Hal ini dijelaskan dalam Undangundang RI Nomor 3 Tahun 2005 tentang Sistem Keolahragaan Nasional. Pada BAB II Pasal 4 dijelaskan sebagai berikut: "Keolahragaan Nasional Bertujuan Memelihara dan Meningkatkan Kesehatan dan Kebugaran, Prestasi, Kualitas Manusia, menanamkan nilai Moral dan Akhlak yang Mulia, Sportivitas, Disiplin, mempererat dan membina persatuan dan kesatuan bangsa, memperkukuh ketahanan nasional, serta mengangkat harkat, martabat dan kehormatan bangsa".

Dalam perkembangannya, olahraga telah menjadi kebutuhan bagi masyarakat untuk menjaga serta meningkatkan kondisi fisik agar tetap bersemangat dalam melaksanakan aktivitas sehari-hari serta memiliki kemampuan untuk berprestasi.

Perkembangan Cabang olahraga bolabasket sangat pesat, sebagai cabang olahraga prestasi, selain mudah dipahami penyelenggaraan pertandingannya pun mudah dilakukan. Selain itu olahraga ini merupakan salah satu cabang olahraga permainan terfavorit Pormal dan non pormal (sekolah diluar sekolah). Tujuan melakukan permainan bolabasket pada dasarnya sama yaitu untuk mendapatkan kesenangan, mendapatkan kesegaran jasmani dan untuk mencapai prestasi yang optimal. Pencapaian prestasi atlet ditentukan dan dipengaruhi oleh banyak faktor.

\section{KAJIAN TEORI}

Menurut Syafrudin (2000) menyatakan bahwa"ada dua factor yang mempengaruhi dalam meraih suatu prestasi, factor internal dan factor eksternal'.faktor internal antara lain: kemampuan fisik, teknik, taktik dan mental (psikis) atlit. Dan factor eksternal yang timbul dari luar diri atlit seperti: pelatih, sarana dan prasarana, guru olahraga, keluarga, organisasi, iklim, cuaca, makanan bergizi dan lain sebagainya”.

Sesuai dengan pendapat Syafruddin tersebut di atas, maka untuk mendapatkan prestasi tinggi pada olahraga bolabasket juga di pengaruhi oleh banyak faktor yaitu faktor dari dalam diri sendiri dan dari luar. Faktor dari dalam diri sendiri yaitu kondisi fisik, teknik, taktik dan mental. Keempat komponen tersebut saling keterkaitan satu sama lainnya, dan faktor luar diri (internal) juga sangat dibutuhkan untuk dapat terlaksananya latihan dengan baik dan tanpa masalah (Paoulus, 2003) 
Dalam perkembangan nya banyak pemain ataupun pelatih yang kurang memperhatikan kemampuan kondisi fisik yang baik dan berdampak pada perestasi yang diraih nya. Ada empat aspek yang harus dilatih dalam pencapaian prestasi yang optimal. Aspek yang perlu diperhatikan meliputi, latihan fisik, latihan teknik, latihan taktik, dan latihan mental. Keempat aspek ini sangat erat kaitannya satu sama lain dalam pencapain prestasi bolabasket.

SMK Negeri 1 Pulau Punjung merupakan salah satu tempat pembinaan bola basket yang ada di Dharmasraya, SMK Negeri 1 Pulau Punjung telah memiliki prestasi yang cukup bagus dibuktikan dengan selalu masuk final dan mendapatkan juara dua di tiga kejuaraan terakhir yang di ikuti. Tetapi team bolabasket SMK Negeri 1 Pulau Punjung ini tidak perna menang pada saat final di tiga kejuaraan terakhir tersebut, team ini selalu mendapatkan juara dua dan juara tiga,

Berdasarkan observasi yang telah peneliti lakukan pada team bolabasket SMK Negeri 1 Pulau Punjung tepat nya pada OSIS Cup yang diadakan oleh SMA Negeri 1 Sitiung, Antar SMA/sedarajat se Kabupaten Dharmasraya, penampilan atlet pada saat pertandingan sangat tidak konsisten, hal ini dipengaruhi oleh beberapa faktor, Kondisi ini jelas terlihat pada saat pertandingan memasuki babak kedua, pada saat babak pertam permainan sangat imbang dan boleh dikatakan tim SMK Negeri 1 Pulau Punjung lebih mendominasi jalannya pertandingan, tapi saat memasuki menit-menit akhir babak kedua atlit SMK Negeri 1 sangat banyak melakukan kesalahan-kesalahan sendiri. Hal ini desebabkan oleh kurangnya daya tahan aerobic $\left(\mathrm{Vo}_{2}\right.$ max) atlit sehinga menyebapkan menurun nya penampilan atlit dalam melakukan aktifitas permainan. Rendah nya tingkat kekuatan atlit mengakibatkan banyak nya terjadi kesalahan-kesalahan mendasar seperti passing yang kurang tepat, shoting yang tidak akurat. Kemudian kurang nya kecepatan atlit berdampak pada saat perpindahan posisi menyerang ke bertahan dan begitu juga sebalik nya. Begitu juga dengan daya ledak otot tangan sehingga menyebabkan kesalahan passing, shooting, dribble yang tidak bagus.

Agar bisa bermain bolabasket, factor kondisi fisik merupakan suatu kehausan yang dimilki, karna kondisi fisik adalah hal yang sangat mendasar dalam menentukan suatu prestasi olahraga. Rendahnya faktor kondisi fisik diduga dapat menyebabkan tidak terealisasikan teknik dan teknik dalam bolabasket. Hal ini yang menyebabkan susah nya pencapaian prestasi dalam bola basket. Sehingga mulai saat ini kondisi fisik atlit harus dibenahi dan ditingkatkan mengingat permainan bolabasket merupakan olahraga yang kompleks dimana factor kondisi fisik sanagt berperan untuk pencapaian prestasi yang optimal.

\section{METODE PENELITIAN}

Jenis penelitian yang digunakan dalam penelitian ini adalah jenis penelitian deskriptif. Sampel adalah suatu jumlah yang terbatas dari unsur-unsur yang terpilih dari suatu populasi". Berdasarkan populasi di atas, maka sampel diambil dengan cara "Purposive Sampling", menurut Sudjana (2009) "Purposive Sampling adalah penentuan sample dilandasi tujuan atau pertimbanganpertimbangan tertentu terlebih dahulu". Dengan demikian pengambilan sampel didasarkan pada maksud yang telah ditetapkan sebelumnya. Maka sampel dalam penelitian ini hanya di ambil atlet putera saja, dengan pertimbangan atlet puteri 
kurang aktif dalam mengikuti latihan, dengan demikian maka jumlah sampel dalam penelitian ini 25 orang.

\section{HASIL PENELITIAN \\ Daya Tahan}

Berdasarkan tabel frekwensi di atas dari 25 orang atlet, ternyata sebanyak 9 orang atlet (36\%) memiliki hasil daya tahan dengan kelas interval 11,55 - 12,35, kemudian sebanyak 5 orang atlet (20\%) memiliki hasil daya tahan dengan kelas interval 12,36 - 13,16, sedangkan sebanyak 6 orang atlet (24\%) memiliki hasil daya tahan dengan kelas interval 13,17 - 13,97, lalu sebanyak 4 orang atlet (16\%) memiliki hasil daya tahan dengan kelas interval 13,98 - 14,78 dan sisanya ada 1 orang atlet lagi (4\%) memiliki hasil daya tahan dengan kelas interval 14,79 15,59. Untuk lebih jelasnya dapat dilihat pada grafik berikut:

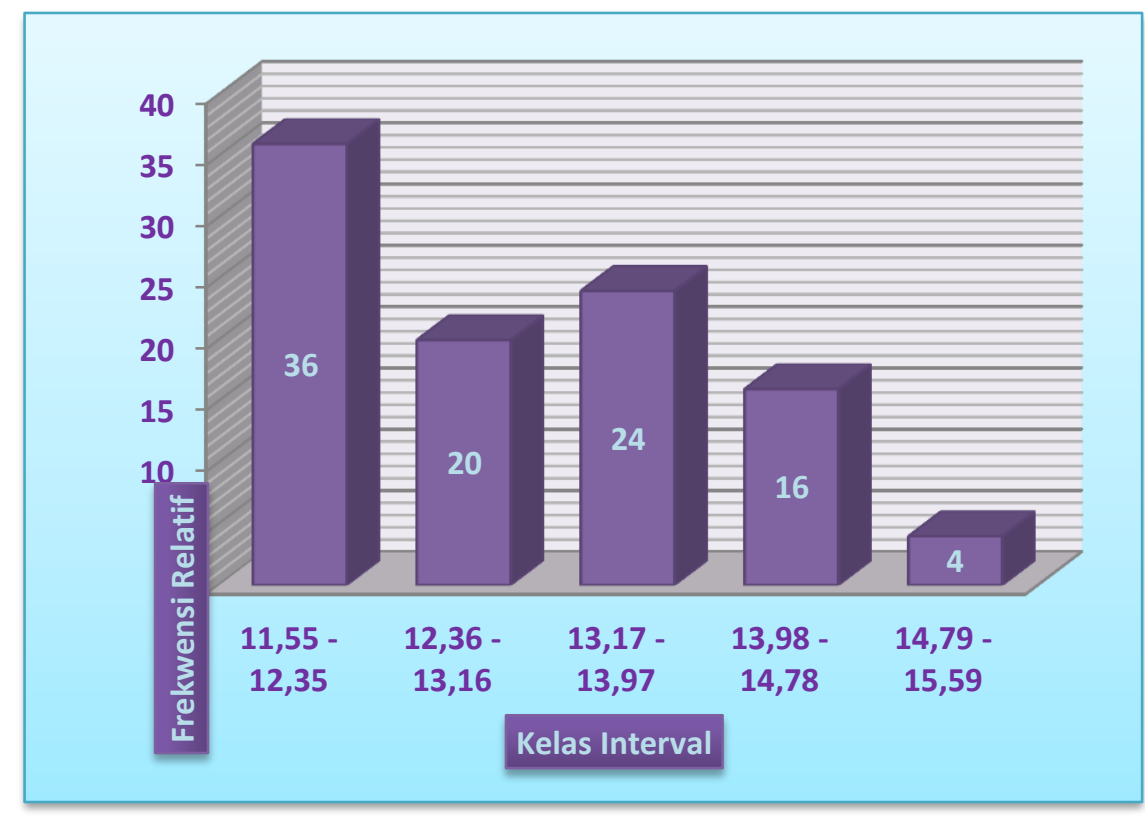

Gambar 1 Daya Tahan

\section{Kekuatan}

Berdasarkan tabel frekwensi di atas dari 25 orang atlet, ternyata sebanyak 7 orang atlet (28\%) memiliki hasil kekuatan dengan kelas interval 62,50 - 67,50, kemudian sebanyak 2 orang atlet (8\%) memiliki hasil kekuatan dengan kelas interval 67,51 - 72,51, lalu sebanyak 6 orang atlet (24\%) memiliki hasil kekuatan dengan kelas interval 72,52 - 77,52, sedangkan sebanyak 9 orang atlet $(36 \%)$ memiliki hasil kekuatan dengan kelas interval 77,53 - 82,53, dan sisanya ada 1 orang atlet lagi (4\%) memiliki hasil kekuatan dengan kelas interval 82,54 - 87,54. Untuk lebih jelasnya dapat dilihat pada grafik berikut 


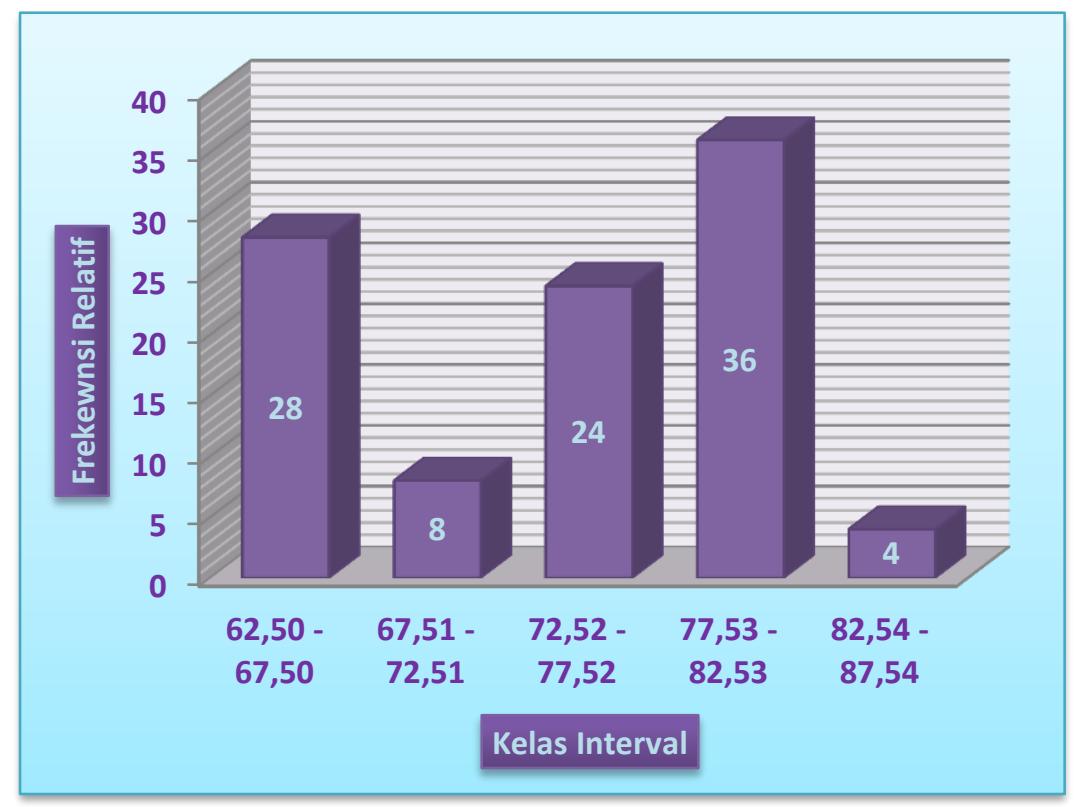

\section{Gambar 2 Kekuatan}

\section{Kecepatan}

Berdasarkan tabel frekwensi di atas dari 25 orang atlet, ternyata sebanyak 13 orang atlet (52\%) memiliki hasil kecepatan dengan kelas interval 4,41 - 5,01, kemudian sebanyak 4 orang atlet $(16 \%)$ memiliki hasil kecepatan dengan kelas interval 5,02 - 5,62, lalu sebanyak 3 orang atlet (12\%) memiliki hasil kecepatan dengan kelas interval 5,63 - 6,23, sedangkan sebanyak 4 orang atlet (16\%) memiliki hasil kecepatan dengan kelas interval 6,24 - 6,84, dan sisanya ada 1 orang atlet lagi (4\%) memiliki hasil kecepatan dengan kelas interval 6,85 - 7,45. Untuk lebih jelasnya dapat dilihat pada grafik berikut

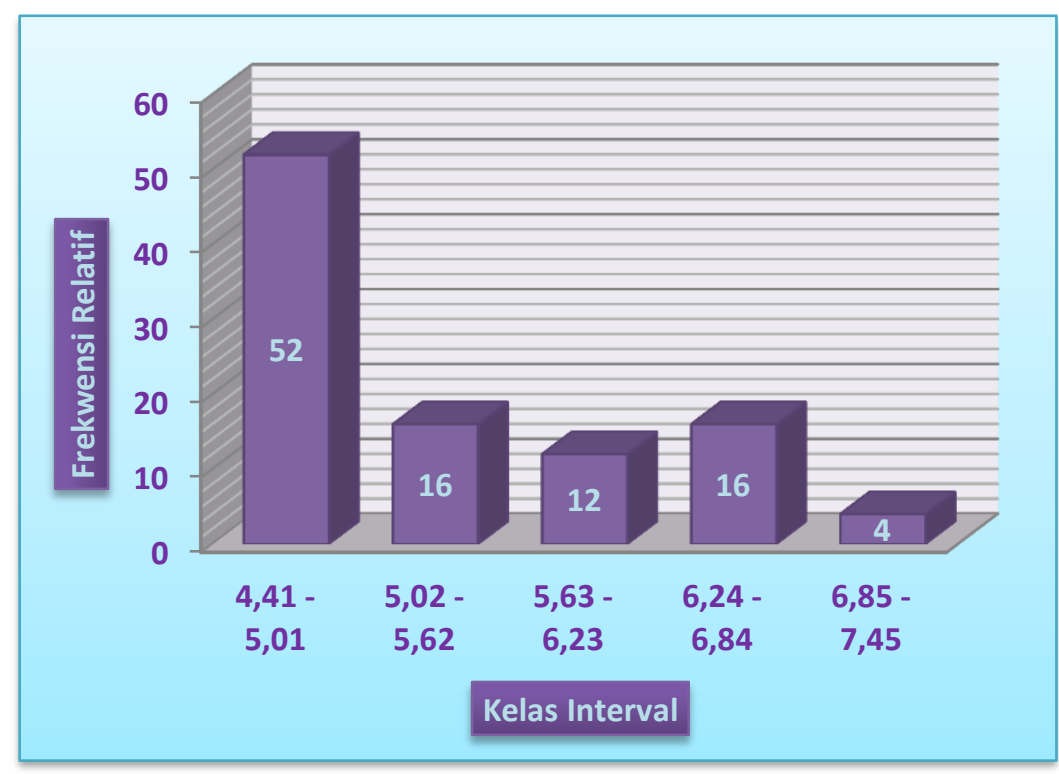

Gambar 3 Kecepatan 


\section{Kelincahan}

Berdasarkan tabel frekwensi di atas dari 25 orang atlet, ternyata sebanyak 8 orang atlet $(32 \%)$ memiliki hasil kelincahan dengan kelas interval $12,10-$ 12,90, kemudian sebanyak 3 orang atlet (12\%) memiliki hasil kelincahan dengan kelas interval 12,91 - 13,71, sedangkan sebanyak 10 orang atlet (40\%) memiliki hasil kelincahan dengan kelas interval 13,72 - 14,52, lalu sebanyak 2 orang atlet (8\%) memiliki hasil kelincahan dengan kelas interval 14,53 - 15,33 dan sisanya ada 2 orang atlet lagi (8\%) memiliki hasil kelincahan dengan kelas interval 15,34 - 16,14. Untuk lebih jelasnya dapat dilihat pada grafik berikut:

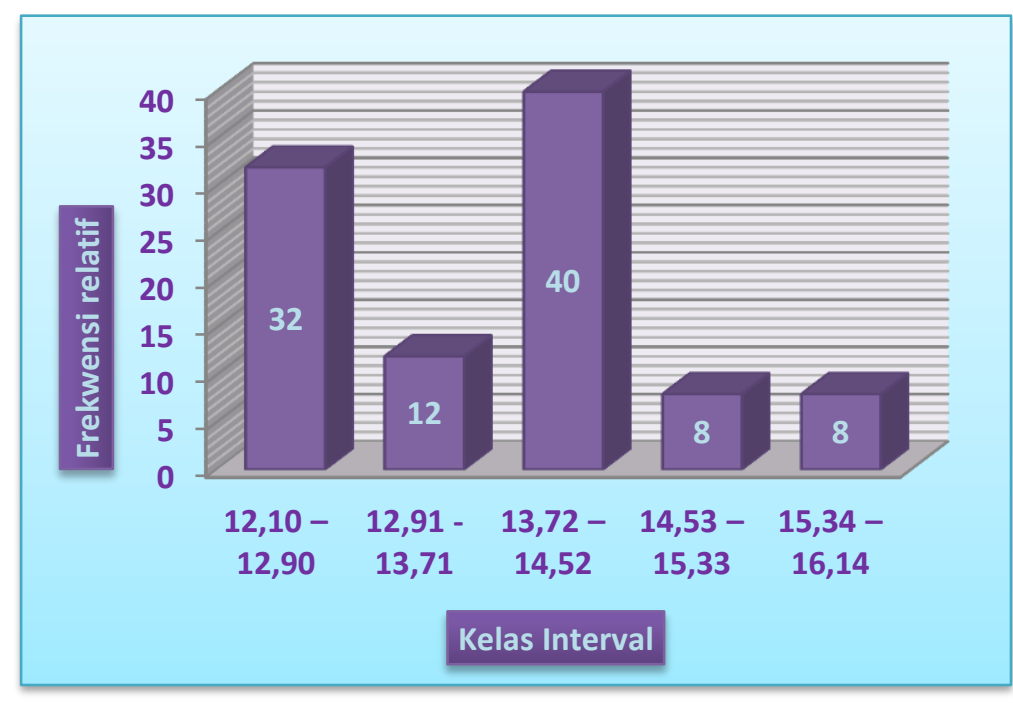

Gambar 4 Kelincahan

\section{Daya ledak otot}

Berdasarkan tabel frekwensi di atas dari 25 orang atlet, ternyata sebanyak 3 orang atlet (12\%) memiliki hasil daya ledak otot tungkai dengan kelas interval 28 - 29, kemudian sebanyak 7 orang atlet $(28 \%)$ memiliki hasil daya ledak otot tungkai dengan kelas interval 30 - 31, sedangkan sebanyak 9 orang atlet $(36 \%)$ memiliki hasil daya ledak otot tungkai dengan kelas interval 32 - 33 dan sisanya ada 6 orang atlet lagi (24\%) memiliki hasil daya ledak otot tungkai dengan kelas interval 34 - 35. Untuk lebih jelasnya dapat dilihat pada grafik berikut:

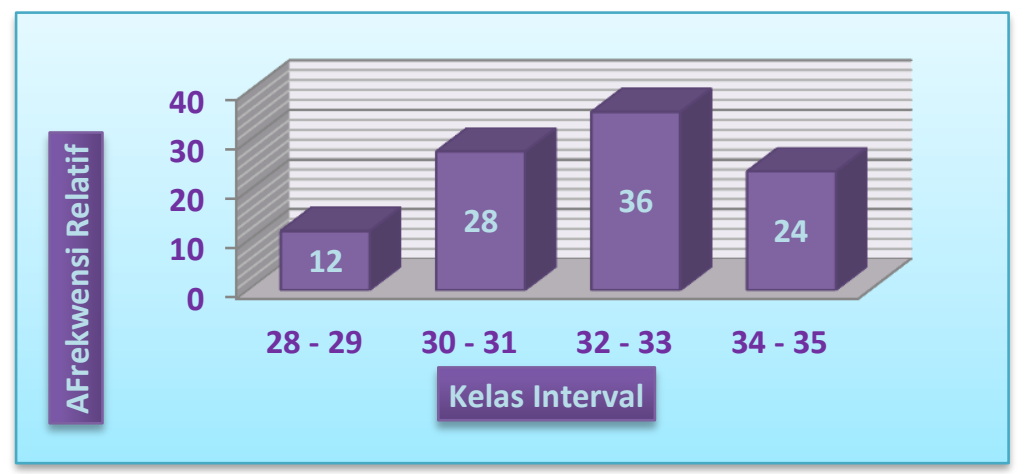

Gambar 5 Daya Ledak Otot 


\section{PEMBAHASAN}

Berdasarkan hasil penelitian yang telah diuraikan pada bab terdahulu dapat dikemukakan kesimpulan bahwa, Tinjauan daya tahan yang dominan dimiliki Atlet Bolabasket SMK Negeri 1 Pulau Punjung jika dibandingkan dengan tabel klasifikasi kesegaran jasmani lari $2.400 \mathrm{~m}$ (dalam menit) adalah 10,59 - 13,25 tergolong kategori baik (60\%). Tinjauan kekuatan yang dominan dimiliki Atlet Bolabasket SMK Negeri 1 Pulau Punjung jika dibandingkan dengan tabel norma standarisasi untuk tes Leg Dynamometer adalah 57,50 - 78,00 tergolong kategori sedang (64\%). Tinjauan kecepatan yang dominan dimiliki Atlet Bolabasket SMK Negeri 1 Pulau Punjung jika dibandingkan dengan tabel norma standarisasi untuk kemampuan tes lari 30 meter adalah 4,97 - 5,40 tergolong kategori sedang (32\%). Tinjauan kelincahan yang dominan dimiliki Atlet Bolabasket SMK Negeri 1 Pulau Punjung jika dibandingkan dengan tabel norma standarisasi kelincahan adalah 14,10 - 15,74 tergolong kategori sedang (14\%). Tinjauan daya ledak otot tungkai yang dominan dimiliki Atlet Bolabasket SMK Negeri 1 Pulau Punjung jika dibandingkan dengan tabel norma standarisasi daya ledak umur 16 s/d 19 tahun adalah 31 - 38 tergolong kategori sedang (72\%).

\section{SIMPULAN}

Tinjauan daya tahan yang dominan dimiliki atlet bolabasket SMK Negeri 1 Pulau Punjung adalah 10,59 - 13,25 tergolong kategori baik (60\%). Tinjauan kekuatan yang dominan dimiliki atlet bolabasket adalah 57,50-78,00 tergolong kategori sedang (64\%), 3). Tinjauan kecepatan yang dominan dimiliki atlet bolabasket SMK Negeri 1 Pulau Punjung adalah 4,97 - 5,40 tergolong kategori sedang (32\%). Tinjauan kelincahan yang dominan dimiliki atlet bolabasket adalah 14,10 - 15,74 tergolong kategori sedang (14\%). Tinjauan daya ledak otot tungkai yang dominan dimiliki atlet bolabasket adalah 31 - 38 tergolong kategori sedang $(72 \%)$.

\section{DAFTAR PUSTAKA}

Pesurney, P. (2003). Latihan Kecepatan. Yogyakarta: Pusat Pendidikan dan Penataran KONI Pusat.

Sudjana. (1999). Metoda Statistik.. Bandung: Transito.

Syafruddin, (2010). Dasar - dasar Kepelatihan Olahraga. Padang: Fakultas Ilmu Keolahragaan Unifersitas Negeri Padang.

Undang-Undang Negara Repbulik Indonesia No.3 (2005). Sistem Keolahragaan Nasional. Bandung : Citra Umbara.

UNP. (2007). Buku Panduan Penulisan Tugas Akhir/ Skripsi Universitas Negeri Padang. Padang: Depdiknas.. 